\title{
P144 Increases Adipose Tissue Volume by Inhibiting TGF- $\beta 1$-Mediated Fibrous Capsule Formation in a Tissue Engineering Chamber
}

\author{
Yaodong Yuan ${ }^{1}$, Jianhua Gao, Zi Jing ${ }^{1}$, Yan Shi ${ }^{1}$, Feng Lu${ }^{1}$, Zhangbo Chen ${ }^{2}$ \\ ${ }^{1}$ Department of Plastic and Cosmetic Surgery, Nanfang Hospital, Southern Medical University, \\ Guangzhou, China \\ ${ }^{2}$ Clinical Laboratory, Shanghai Tenth People's Hospital, Shanghai, China \\ Email: cat_love_guai@163.com
}

How to cite this paper: Yuan, Y.D., Gao, J.H., Jing, Z., Shi, Y., Lu, F. and Chen, Z.B. (2021) P144 Increases Adipose Tissue Volume by Inhibiting TGF- $\beta 1$-Mediated Fibrous Capsule Formation in a Tissue Engineering Chamber. Journal of Biosciences and Medicines, 9, 98-109.

https://doi.org/10.4236/jbm.2021.912008

Received: November 3, 2021

Accepted: December 10, 2021

Published: December 13, 2021

Copyright $\odot 2021$ by author(s) and Scientific Research Publishing Inc. This work is licensed under the Creative Commons Attribution International License (CC BY 4.0).

http://creativecommons.org/licenses/by/4.0/

(c) (i) Open Access

\begin{abstract}
Tissue engineering chambers (TECs) represent a new and attractive in vivo tissue engineering model that can successfully generate mature adipose tissue. However, the newly formed adipose tissue is not able to fill the volume of the chamber as expected. To investigate whether the capsule surrounding the newly formed adipose tissue limits the adipose tissue volume in the chamber, we detected fibrotic parameters two months after these chambers were implanted into rats. The results showed that the newly formed adipose tissue was surrounded by a thick layer of capsule, and the protein levels of transforming growth factor- $\beta 1$ (TGF- $\beta 1$ ), phosphorylated Smad2 (p-Smad2), connective tissue growth factor (CTGF), collagen type I (COL-I) and $\alpha$-smooth muscle actin ( $\alpha$-SMA) in the capsule were increased. The levels of these proteins decreased following systemic administration of P144 (a peptide inhibitor of TGF- $\beta 1$ ). Furthermore, the capsule thickness was significantly reduced, and the adipose tissue volume was markedly greater when using P144. These findings indicate that capsule formation, which is mediated through a TGF$\beta 1$ signaling pathway, restricted the volume of the engineered adipose tissue that was formed. This study may provide a new approach to regenerate amounts of adipose tissue for the reconstruction of large soft tissue defects.
\end{abstract}

\section{Keywords}

Adipose Tissue, Tissue Engineering Chamber, Capsule Formation, Transforming Growth Factor- $\beta 1$, P144 


\section{Introduction}

The repair of large soft tissue defects after wound or surgical resection represents a major challenge for reconstructive surgery, and the best tissue for such coverage is the one that is similar to the original. Current approaches such as autologous fat grafting or fat flap transplantation have limitations that include resorption and donorsite morbidity [1] [2]. Tissue engineering chambers (TECs) represent a new and attractive in vivo tissue engineering technique that can successfully generate mature and vascularized adipose tissue through the insertion of a pedicled fat flap into a hollow chamber that is implanted subcutaneously [3] [4] [5] [6]. However, the newly formed engineered adipose tissue does not fill the volume of the chamber as expected. Furthermore, the whole tissue harvested from these chambers is surrounded by a thick capsule layer, and the percentage of adipose tissue is lower than that of connective tissue in the newly formed engineered tissue constructs [3] [5]. Therefore, further refinements are required to enhance fat formation and to increase adipose tissue volume.

Capsule formation, which is characterized by fibrotic encapsulation around an implant, can be seen as an inevitable foreign body reaction when an implant is placed within the body [7]. Transforming growth factor- $\beta 1$ (TGF- $\beta 1$ ) is considered to be a major profibrotic cytokine involved in the formation of the capsule around the implant [8]. TGF- $\beta 1$ can phosphorylate its downstream effector Smad2 and enhance the profibrotic mediator connective tissue growth factor (CTGF), which consequently induces fibrosis-related changes, including stimulation of myofibroblasts proliferation and promotion collagen deposition [9]. In our preliminary experiments, we found that in a special TEC model, the capsule formed not only around the chamber but also around the newly formed adipose tissue in the chamber, which was referred to as the "adipose capsule". However, the mechanism of adipose capsule formation and whether the capsule limits the volume of the engineered adipose tissue in the TEC model are unknown.

Recent studies have shown that the synthetic peptide P144, which is composed of 730 - 743 amino acids derived from the membrane-proximal ligand-binding domain of the TGF- $\beta 1$ type III receptor, is able to block the biological activity of TGF- $\beta 1$ by binding to its receptors [10] [11]. Systemic administration of this peptide has shown good efficacy in animal models of myocardial fibrosis, liver fibrogenesis and skin fibrosis [11] [12] [13]. Moreover, P144 has been demonstrated to reduce capsule formation around silicone implants through the inhibition of TGF- $\beta 1$ [14].

In this study, we sought to examine whether the adipose capsule in the chamber limits the volume of engineered adipose tissue. Furthermore, to examine whether TGF- $\beta 1$ signaling pathway involves in adipose capsule formation, we assessed the effect of P144 on adipose capsule thickness and adipose tissue volume.

\section{Methods}

\subsection{Animals and Chambers}

Adult male Sprague-Dawley rats weighing 350 to $400 \mathrm{~g}$ were used. All experi- 
ments described herein were performed under the approval of the Shanghai Tenth People's Hospital Institutional Animal Care and Use Committee. Noncollapsible half-cylindrical chambers with a length of $20 \mathrm{~mm}$, an internal diameter of $16 \mathrm{~mm}$ and a volume of $2.01 \mathrm{ml}$ were used.

\subsection{Experimental Design}

The experimental groups were organized as follows. Standard fat (SF) group: six standardized vascularized adipose tissue groin flaps (dimensions: $20 \times 10 \times 1.3$ $\mathrm{mm}$ ) were harvested at day 0 . All of the fat flaps in all of the experimental groups were measured and trimmed to this size. Control fat (CF) group: fat flaps remained in situ in the subcutaneous tissue of the groin without any chamber ( $\mathrm{n}=$ 6). Tissue engineering chamber (TEC) group: standardized vascularized fat groin flap in a chamber ( $n=6$ chambers). Vehicle-treated TEC (V-TEC) group: after the chambers were implanted, the rats were administered an intraperitoneal injection of normal saline solution at $1 \mathrm{ml} / \mathrm{kg}$ per day from day 7 until sacrifice $(\mathrm{n}=6$ chambers). P144-treated TEC (P144-TEC) group: after the chambers were implanted, the rats were administered an intraperitoneal injection of P144 daily. This group was divided into four subgroups depending on the initiation of P144 injections. The injections started on days 7 (P144-7th), 14 (P144-14th), 21 (P14421st) and 30 (P144-30th) after the chambers were implanted ( $\mathrm{n}=6$ chambers per time point). P144 (sequence: TSLDASIWAMMQNA, synthesized at ChinaPeptides, Shanghai, China; the peptides were at least $95 \%$ pure, as per HPLC) was dissolved in normal saline solution and was adjusted to an average daily dose of $1 \mathrm{mg} / \mathrm{kg}$. All animals were sacrificed two months after the surgery, except for the CF group.

\subsection{Surgical Techniques}

The surgical techniques were performed as described by Dolderer et al., with some modifications [3]. Rats were anesthetized via intraperitoneal injection of $60 \mathrm{mg} / \mathrm{kg}$ sodium pentobarbital (Sigma Chemical Co., USA). Under aseptic conditions, the standard vascularized groin fat pad was surgically exposed. Then, the fat pad was inserted into the chamber, which was placed and fixed in the space created between the skin and muscle. Each rat was implanted with two chambers, and the wound was closed with 5-0 silk sutures.

\subsection{Tissue Harvesting and Histological Examinations}

The tissue constructs were harvested from the chambers after two months, and the total tissue volume was measured via fluid displacement [15]. Then, the constructs were cut coronally into two symmetrical pieces. In one of the pieces, the adipose capsule was dissected from the tissue and was frozen for protein analysis. The other piece was used for hematoxylin and eosin (H\&E) and Masson's trichrome staining. Slides were evaluated using an Olympus BX51 microscope and then photographed using an Olympus DP71 digital camera. 


\subsection{Adipose Capsule Thickness}

In this study, the measured adipose capsule thickness included the collagen and fibrovascular connective tissue, as these are the most common tissues characteristic of the capsule [16]. Adipose capsule thickness was evaluated by two independent examiners using Image Pro Plus. Each examiner performed 10 random measurements per slide, and the mean of the 20 measurements was recorded as the adipose capsule thickness for that slide. Both examiners were blinded to the experimental groups of the samples.

\subsection{Western Blot Analysis}

The TGF- $\beta 1$, the phosphorylated form of Smad2 (p-Smad2), CTGF and collagen type I (COL-I) proteins were separated via electrophoresis. Specific antibodies against TGF- $\beta 1$ (Santa Cruz Biotechnology, USA), p-Smad2 (Abcam, UK), CTGF (Abcam, UK) and COL-I (Santa Cruz Biotechnology, USA) were incubated overnight. Data are reported relative to $\beta$-actin expression.

\subsection{Immunohistochemistry for $\alpha$-SMA}

Immunohistochemical analyses were performed using a rabbit anti-rat $\alpha$-SMA antibody (Abcam, UK). The steps were identical to those described in a previous study by our group [17]. Briefly, the primary antibody was diluted 1:300 and was incubated with the slides overnight. Then, the slides were incubated with a secondary antibody (Abcam, UK) diluted 1:200.

\subsection{Statistical Analysis}

Statistical analyses were performed using SPSS 13.0. Comparisons between two groups were analyzed using independent sample t-tests, and when there were more than two groups, one-way ANOVA was used. A Spearman correlation analysis was conducted between adi-pose tissue volume and adipose capsule thickness. Differences were considered statistically significant at $\mathrm{p}<0.05$. The data are expressed as the mean $\pm \mathrm{SD}$.

\section{Results}

\subsection{Macroscopic Appearance and Fibrotic Parameters after Chamber Implantation}

The volume of the fat flap in the CF group, which was dissected in situ after two months, remained at $0.26 \pm 0.02 \mathrm{ml}$, exhibiting no obvious expansion (Figure $1(\mathrm{~A})$ ). The volume of the harvested tissue in the TEC group was significantly increased to a large volume $(1.05 \pm 0.03 \mathrm{ml})$, which represents an increase of 404\% (Figure 1(B)). Histological analysis showed that the CF group displayed mature adipose tissue with no capsule formation (Figure $1(C)$ ), whereas in the TEC group, the adipose tissue was surrounded by a thick capsule layer (Figure $1(D))$. To examine whether the implanted chambers caused a fibrosis reaction, we detected fibrotic parameters related to TGF- $\beta 1$. The results show that the 

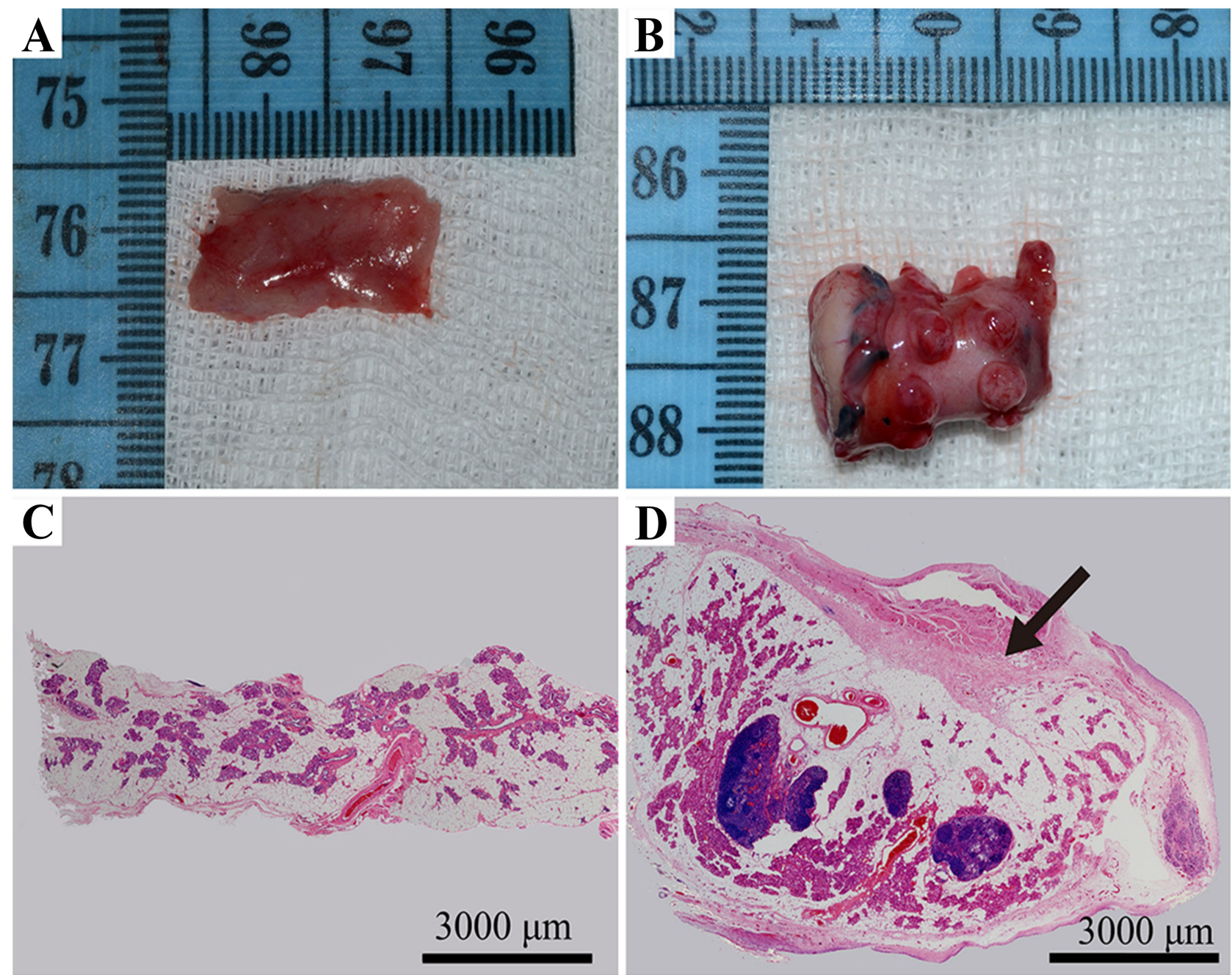

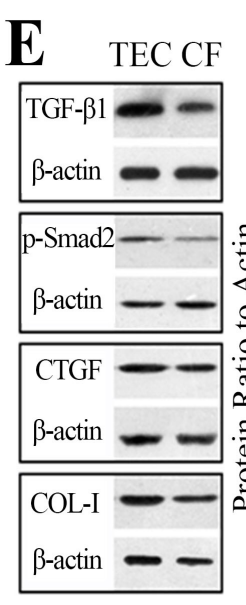

TEC CF
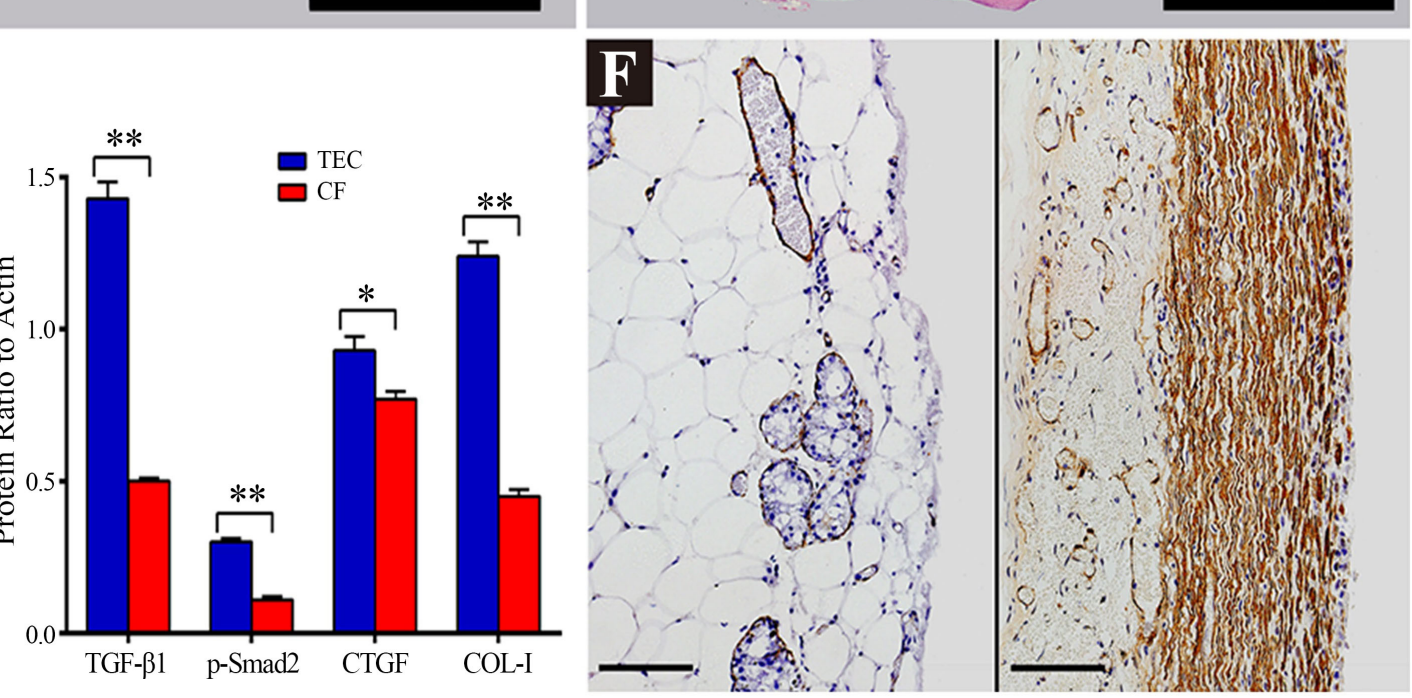

Figure 1. Macroscopic appearance and fibrotic parameters after the chambers were implanted. The amount of tissue harvested from the TEC group (B) was significantly greater than from the CF group (A). H\&E staining revealed mature adipose tissue and some breast gland/epithelial structures in the CF group (C), but the mature adipose tissue was surrounded by a thick adipose capsule layer (D, arrow). C and D scale bar $=3000 \mu \mathrm{m}$. (E) TGF- $\beta 1, p$-smad2, CTGF and COL-I protein levels were greater in the TEC group vs. the CF group. ${ }^{*} \mathrm{p}<0.05$ and ${ }^{* *} \mathrm{p}<0.01$ vs. CF group. (F) Left: CF group; Right: TEC group. Immunohistochemical analysis showed intense staining of $\alpha$-SMA-positive myofibroblasts in the adipose capsule in the TEC group. Scale bar $=100 \mu \mathrm{m}$. 
protein levels of TGF- $\beta 1$ and its related signaling molecules, including $\mathrm{p}$-smad2 and CTGF, were greater in the TEC group compared with the CF group (TGF- $\beta 1$ $(\mathrm{p}<0.01)$, $\mathrm{p}$-smad2 $(\mathrm{p}<0.01)$, CTGF $(\mathrm{p}<0.05))$. Moreover, the synthesis of COL-I was also increased ( $\mathrm{p}<0.01$ ) (Figure $1(\mathrm{E})$ ). $\alpha$-SMA is thought to be responsible for tissue contracture [18]. Immunohistochemical staining showed intense accumulation of $\alpha$-SMA in the adipose capsule in the TEC group (Figure 1(F)).

\subsection{P144 Increases Adipose Tissue Volume and Decreases Adipose Capsule Thickness}

To inhibit adipose capsule formation, rats were administered an intraperitoneal injection of P144 (1 mg/kg, q.d.). There was no difference in adipose tissue volume observed between the TEC and V-TEC groups. The adipose tissue volume in the P144-treated groups was obviously greater than in the V-TEC group ( $\mathrm{p}<$ 0.01 ) (Figures 2(A)-(F)). Moreover, the adipose tissue volumes in the P144-7th and P144-14th group were markedly greater than in the P144-30th group ( $\mathrm{p}<$ 0.01). Furthermore, the proportion of adipose tissue in the P144-treated groups was obviously greater than in the V-TEC group $(\mathrm{p}<0.01)$ (Table 1$)$. To better demonstrate adipose capsule formation in the tissue, the harvested tissue was stained with Masson's trichrome, which reveals areas of collagen (blue) (Figures 2(A)-(F)). The results showed that the administration of P144 significantly reduced adipose capsule thickness compared with the V-TEC group $(\mathrm{p}<0.01)$. Moreover, the adipose capsule thicknesses recorded in the P144-7th and P14414th groups were significantly decreased compared with the P144-30th and P144-21st groups $(\mathrm{p}<0.01)$. Although the adipose capsule thickness in the P1447th group was thinner than in the P144-14th group, the difference was not significant (Table 1). Spearman correlation analysis revealed a strong negative correlation between adipose capsule thickness and adipose tissue volume $(\mathrm{r}=-0.853$, $\mathrm{p}<0.001$ ) (Supp. Figure 2). Taken together, these findings show that the administration of P144 decreases adipose capsule thickness and increases adipose tissue volume and the proportion of adipose tissue.

Table 1. The effect of P144 on adipose capsule thickness, the total volume of the tissue construct, adipose tissue volume and the proportion of adipose tissue.

\begin{tabular}{ccccc}
\hline Group & Thickness $(\mu \mathrm{m})$ & TV $(\mathrm{ml})$ & AV $(\mathrm{ml})$ & AT $(\%)$ \\
\hline TEC & $1066.04 \pm 101.43$ & $1.05 \pm 0.05$ & $0.45 \pm 0.03$ & $43.02 \pm 3.36$ \\
V-TEC & $1098.57 \pm 105.18 \#, \&$ & $1.05 \pm 0.04 \#, \&$ & $0.45 \pm 0.02 \#, \&$ & $43.23 \pm 2.26 \#, \&$ \\
P144-30th & $800.06 \pm 173.39^{\star}, \#, \&$ & $0.36 \pm 0.06^{\star}, \#, \&$ & $0.67 \pm 0.07^{\star}, \#, \&$ & $49.43 \pm 4.40^{*}, \#$ \\
P144-21st & $705.83 \pm 95.07^{\star}, \#, \&$ & $1.41 \pm 0.06^{\star}, \#, \&$ & $0.73 \pm 0.08^{\star}$ & $51.88 \pm 4.11^{\star}$ \\
P144-14th & $449.25 \pm 101.30^{\star}$ & $1.58 \pm 0.08^{\star}$ & $0.88 \pm 0.09^{\star}$ & $55.15 \pm 4.03^{*}$ \\
P144-7th & $349.33 \pm 48.72^{\star}$ & $0.63 \pm 0.07^{*}$ & $0.89 \pm 0.08^{\star}$ & $54.32 \pm 4.27^{*}$ \\
\hline
\end{tabular}

The presented data are the mean $\pm \mathrm{SD} ;{ }^{\star} \mathrm{p}<0.01$ vs. V-TEC; $\# \mathrm{p}<0.01$ vs. P144-14th; \&p $<0.01$ vs. P144-7th. Thickness, adipose capsule thickness; TV, total volume of the tissue construct; AV, adipose tissue volume; AT, percentage of adipose tissue. 

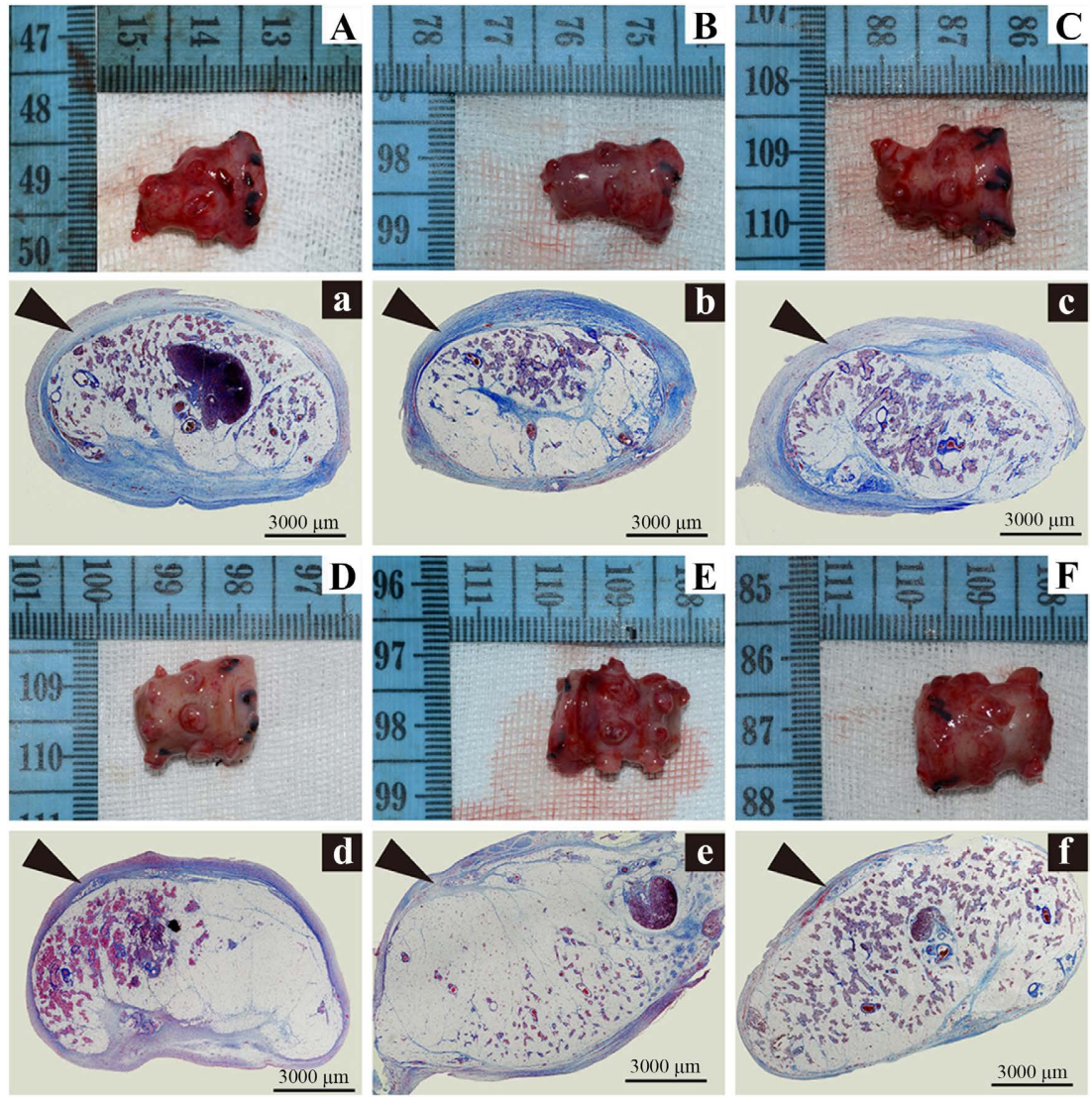

Figure 2. Effect of P144 on tissue volume and adipose capsule thickness. Tissue volume was significantly increased (A)-(F); adipose capsule thickness was significantly decreased; and the use of P144 caused a reduced density of the collagen fibers (a)-(f). (A)-(F) Macroscopic appearance. (a)-(f) Masson's trichrome staining after paraffin sectioning. (A), (a) TEC group; (B), (b) V-TEC; (C), (c) P144-30th; (D), (d) P144-21st; (E), (e) P14414th; (F), (f) P144-7th. The arrowhead indicates a peripheral adipose capsule surrounding the fat tissue. (a)-(f) Scale bar $=3000 \mu \mathrm{m}$.

\subsection{P144 Inhibits TGF- $\beta 1$ Signaling Activity and COL-I Synthesis}

To elucidate the mechanism of the effect of P144 on adipose capsule formation, we assessed the protein levels of fibrotic parameters. No differences were found between the V-TEC and the TEC groups with respect to these fibrotic parameters. The expression of the TGF- $\beta 1$ ( $p<0.01)$, $\mathrm{p}$-smad2 $(\mathrm{p}<0.01)$ and CTGF ( $\mathrm{p}$ $<0.01$ ) proteins was obviously reduced under P144 treatment compared with the V-TEC group (Figure 3(A)). Moreover, the P144-treated groups showed greater expression of the COL-I protein $(\mathrm{p}<0.01)$ than the V-TEC group (Figure $3(\mathrm{~B})$ ). Additionally, the inhibition described above was more effective when applied in the early stage of capsule formation.

\subsection{P144 Inhibits TGF- $\beta 1$ Signaling Activity and COL-I Synthesis}

We next performed immunohistochemical staining to evaluate the effect of P144 on myofibroblasts proliferation in the tissue. Semiquantitative immunohistochemical analyses of $\alpha$-SMA revealed a significant decrease $(\mathrm{p}<0.01)$ in the 


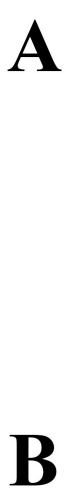

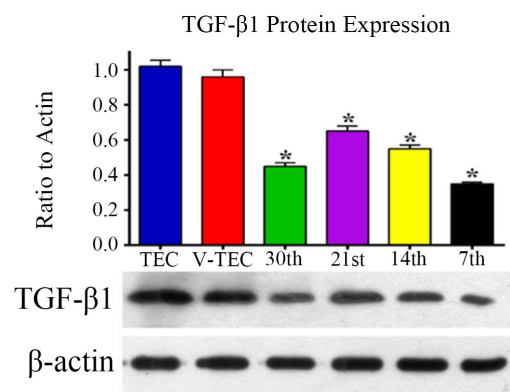

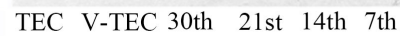

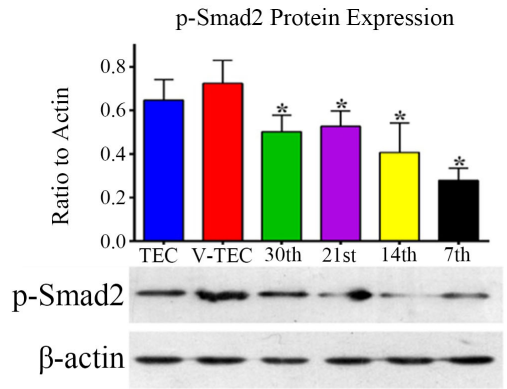

TEC V-TEC 30th 21st 14th 7th

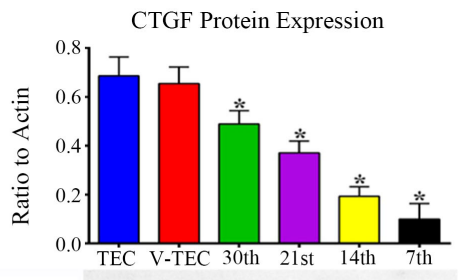

$\mathrm{CTGF}-\cdots-\ldots$

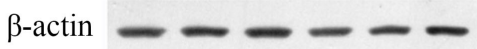

TEC V-TEC 30th 21st 14th 7th
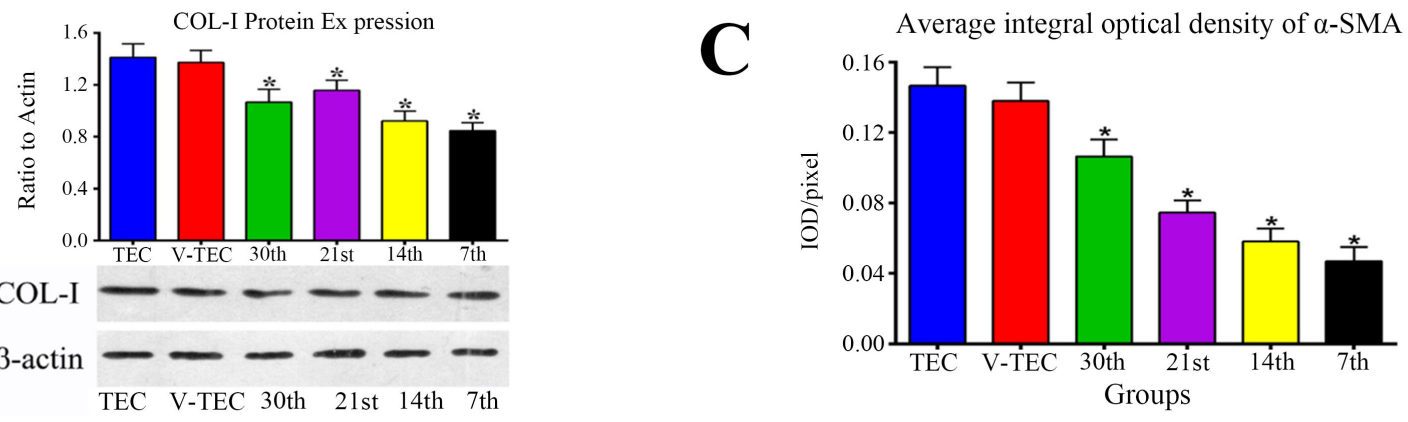

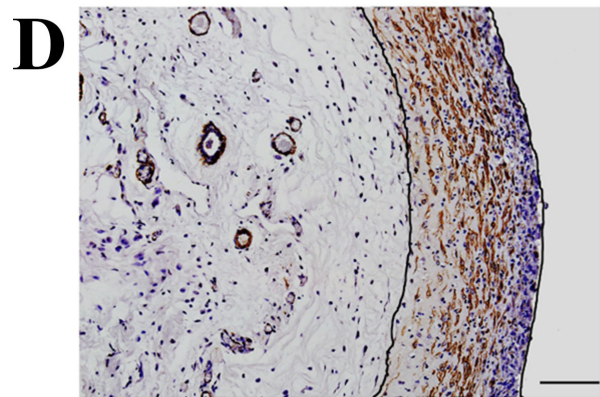

TEC

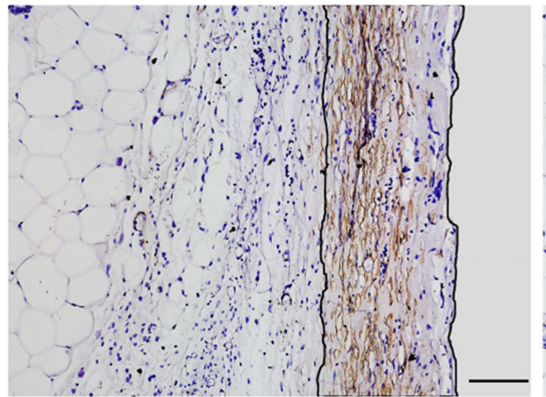

$21 \mathrm{st}$

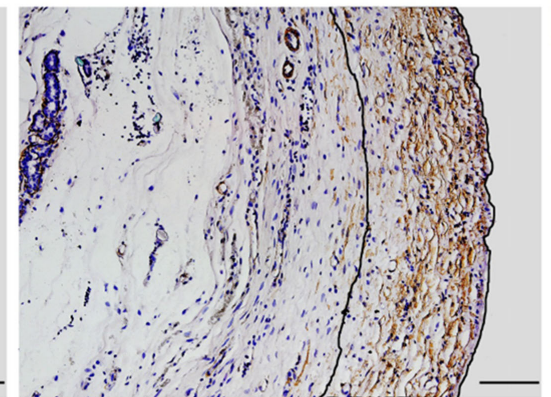

$\mathrm{V}-\mathrm{TEC}$

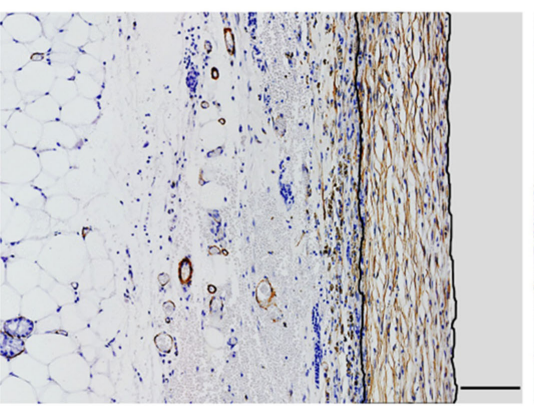

14 th

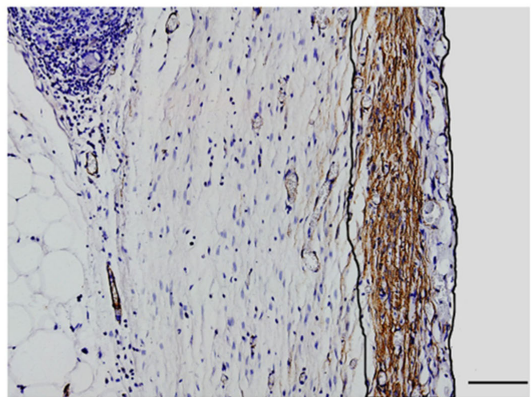

30 th

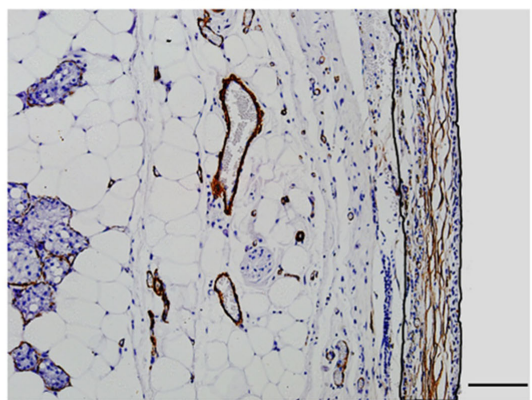

7 th

Figure 3. Effect of P144 on TGF- $\beta 1$ signaling activity, COL-I synthesis and myofibroblasts proliferation. Systemic administration of P144 reduced the expression of the TGF- $\beta 1$ (A left), p-Smad2 (A middle) and CTGF (A right) proteins. (B) The use of P144 inhibited COL-I synthesis. (C) Average integral optical density of $\alpha$-SMA. (D) Immunohistochemical staining for $\alpha$-SMA was performed in the TEC, V-TEC, P144-30th, P144-21st, P144-14th and P144-7th groups. The P144-treated groups exhibited fewer myofibroblasts than the V-TEC group. The area within the black lines was used to calculate the $\alpha$-SMA density. Scale bar $=300$ $\mu \mathrm{m} .{ }^{*} \mathrm{p}<0.01$ vs. the V-TEC group. Error bars $=$ SD.

P144-treated groups compared with the V-TEC group (Figure 3(C), Figure 3(D)). These results showed that the proliferation of myofibroblasts was obviously decreased by P144 treatment, and this effect was more effective at an early stage. 


\section{Discussion}

In the special TEC model, pedicled fat flaps were implanted subcutaneously into a hollow silicone chamber to generate a large volume of engineered adipose tissue, and the newly formed adipose tissue was surrounded by a thick capsule layer [3] [5]. However, little is known regarding the role of the adipose capsule in the chambers. In this study, we found that the adipose capsule restricts the formation of a larger volume of engineered adipose tissue. Moreover, the administration of $\mathrm{P} 144$ reduced adipose capsule formation by inhibiting the activity of TGF- $\beta 1$, which indicates that the TGF- $\beta 1$ signaling pathway plays a critical role in the adipose capsule.

An adipose capsule has been observed to form in the TEC, but the formation mechanism was not clear. Kuhn et al. reported the detection of high levels of TGF- $\beta 1$ in the capsule around the implant [8]. Therefore, we hypothesized that the adipose capsule is mediated by TGF- $\beta 1$ as well. In a previous, we study demonstrated that the structure of the newly formed adipose tissue in the TEC was well organized at two months [17], so we selected two months as the follow-up time point for this study. We found that the adipose capsule expressed a high 10 level of TGF- $\beta 1$ after the chamber was implanted. This result implies that TGF- $\beta 1$ might be involved in the formation of the adipose capsule. To confirm our hypothesis, we inhibited the activity of TGF- $\beta 1$. The synthesis of the P144 peptide opened the door to exploring new substances that inhibit TGF- $\beta 1$ activity and have antifibrotic effects [12] [13]. In this study, the selected dose of the peptide was adjusted to $1 \mathrm{mg} / \mathrm{kg}$ per day intra-peritoneally, as this dose has been previously demonstrated to result in significant antifibrotic activity in rodents [11] [12]. We found that the adipose capsule formed at two weeks (data not shown). For this reason, rats were treated with P144 starting at four time points (at days 7, 14, 21 and 30 after the surgery) two of which were prior to and two of which were after adipose capsule formation. The results revealed that the application of P144 at four time points was feasible in reducing adipose capsule thickness through the inhibition of TGF- $\beta 1$; however, the administration of P144 during an early stage (starting at day 7 and 14) was more effective. Therefore, we can conclude that adipose capsule formation is mediated by TGF- $\beta 1$.

Next, we observed the effect of TGF- $\beta 1$-related signaling molecules on the formation of the adipose capsule. After binding to its receptor, TGF- $\beta 1$ phosphorylates Smad2/3 (which are intracellular signal mediators), forms a heteromeric complex with Smad4 and regulates the transcription of TGF- $\beta 1$-responsive genes [9]. CTGF is an important downstream mediator of TGF- $\beta 1$, and the profibrotic effects of TGF- $\beta 1$ are mediated, at least in part, through upregulation of CTGF [16]. In the present study, we found that the adipose capsule expressed high levels of p-Smad2 and CTGF after the chambers were implanted. Following P144 treatment, the inhibition of TGF- $\beta 1$ activity resulted in inhibition of $\mathrm{p}$-Smad2 and CTGF expression. Therefore, P144 reduced adipose capsule formation through the inhibition of p-Smad2 and CTGF.

In vitro studies have shown that TGF- $\beta 1$ can stimulate fibroblasts to synthes- 
ize COL-I, which is a common hallmark of fibrous capsules [19]. Masson's stain, which reveals areas of collagen, showed that the adipose capsule is composed of dense layers of collagen. After the application of P144, the collagen fibers were thinner and less dense, showing a loose and organized pattern, and the level of COL-I protein was also decreased. Furthermore, the 11 adipose capsule thickness was found to be negatively correlated with the adipose tissue volume. Therefore, P144 reduced the synthesis of COL-I through the inhibition of TGF- $\beta 1$ activity, which appears to be a promising approach for reducing COL-I synthesis.

Furthermore, when subjected to TGF- $\beta 1$ stimulation, fibroblasts are activated and transdifferentiate into myofibroblasts that express $\alpha$-SMA, which is thought to be responsible for tissue contracture [18]. We found that the expression of myofibroblasts increased after the chambers were implanted. Tissue expansion is one of the most frequently used reconstructive techniques for generating sufficient skin, through implanting a silicone sac subcutaneously and regularly injecting saline into it [20]. After implantation, the tissue expander is surrounded by a fibrosis capsule that expresses $\alpha$-SMA [21]. It appears that the TEC model is similar to a tissue expander. Both are used to enlarge tissue (skin tissue in the case of the tissue expander and adipose tissue in the case of the TEC model), and both form a capsule layer that expresses $\alpha$-SMA around the increscent tissue. Experiments have demonstrated that inhibiting the expression of $\alpha$-SMA can accelerate the process of tissue expansion in the capsule around the tissue expander [22] [23]. Therefore, we explored whether adipose.

\section{Conclusion}

This study explored that the formation of capsules on the surface of engineered adipose tissue is related to TGF- $\beta 1$. Moreover, as a blocker of TGF- $\beta 1$ signaling, P144 can reduce the formation of capsules around silicone implants by inhibiting TGF- $\beta 1$, thereby provide a new approach to regenerating amounts of adipose tissue for the reconstruction of large soft tissue defects.

\section{Fund}

This work was supported by the National Nature Science Foundation of China 81372083, 81071589.

\section{Conflicts of Interest}

The authors declare no conflicts of interest regarding the publication of this paper.

\section{References}

[1] Vyas, R.M., Dickinson, B.P., Fastekjian, J.H., Watson, J.P., Dalio, A.L. and Crisera, C.A. (2008) Risk Factors for Abdominal Donor-Site Morbidity in Free Flap Breast Reconstruction. Plastic and Reconstructive Surgery, 121, 1519-1526. https://doi.org/10.1097/PRS.0b013e31816b1458

[2] Bucky, L.P. and Percec, I. (2008) The Science of Autologous Fat Grafting: Views on 
Current and Future Approaches to Neoadipogenesis. Aesthetic Surgery Journal, 28, 313-321. https://doi.org/10.1016/j.asj.2008.02.004

[3] Dolderer, J.H., Abberton, K.M., Thompson, E.W., Slavin, J.L., Stevens, G.W., Penington, A.J. and Morrison, W.A. (2007) Spontaneous Large Volume Adipose Tissue Generation from a Vascularized Pedicled Fat Flap Inside a Chamber Space. Tissue Engineering, 13, 673-681. https://doi.org/10.1089/ten.2006.0212

[4] Findlay, M.W., Messina, A., Thompson, E.W. and Morrison, W.A. (2009) LongTerm Persistence of Tissue-Engineered Adipose Flaps in a Murine Model to 1 Year: An Update. Plastic and Reconstructive Surgery, 124, 1077-1084. https://doi.org/10.1097/PRS.0b013e3181b59ff6

[5] Dolderer, J.H., Thompson, E.W., Slavin, J., Trost, N., Cooper-White, J.J., Cao, Y., O'Con-nor, A.J., Penington, A., Morrison, W.A. and Abberton, K.M. (2011) LongTerm Stability of Adipose Tissue Generated from a Vascularized Pedicled Fat Flap Inside a Chamber. Plastic and Reconstructive Surgery, 127, 2283-2292.

https://doi.org/10.1097/PRS.0b013e3182131c3e

[6] Findlay, M.W., Dolderer, J.H., Trost, N., Craft, R.O., Cao, Y., Cooper-White, J., Stevens G. and Morrison, W.A. (2011) Tissue-Engineered Breast Reconstruction: Bridging the Gap toward Large-Volume Tissue Engineering in Humans. Plastic and Reconstructive Surgery, 128, 1206-1215. https://doi.org/10.1097/PRS.0b013e318230c5b2

[7] Bassetto, F., Scarpa, C., Vindigni, V. and Doria, A. (2012) The Periprosthetic Capsule and Connective Tissue Diseases: A Piece in the Puzzle of Autoimmune/Autoinflammatory Syndrome Induced by Adjuvants. Experimental Biology and Medicine, 237, 1117-1122. https://doi.org/10.1258/ebm.2012.012151

[8] Kuhn, A., Singh, S., Smith, P.D., Ko, F., Falcone, R., Lyle, W.G., Maggi, S.P., Wells, K.E. and Robson, M.C. (2000) Periprosthetic Breast Capsules Contain the fibrogenic cytokines TGF-beta1 and TGF-beta2, suggesting possible new treatment approaches. Annals of Plastic Surgery, 44, 387-391. https://doi.org/10.1097/00000637-200044040-00006

[9] Biernacka, A., Dobaczewski, M. and Frangogiannis, N.G. (2011) TGF-Beta Signaling in Fibrosis. Growth Factors, 29, 196-202. https://doi.org/10.3109/08977194.2011.595714

[10] Zarranz-Ventura, J., Fernandez-Robredo, P., Recalde, S., Salinas-Alaman, A., Borras-Cuesta, F., Dotor, J. and Garcia-Layana, A. (2013) Transforming Growth Factor-Beta Inhibition Reduces Pro-Gression of Early Choroidal Neovascularization Lesions in Rats: P17 and P144 Peptides. PLoS ONE, 8, Article ID: e65434. https://doi.org/10.1371/journal.pone.0065434

[11] Hermida, N., López, B., González, A., Dotor, J., Lasarte, J.J., Sarobe, P., et al. (2009) A Synthetic Peptide from Transforming Growth Factor-Betal Type III Receptor Prevents My-Ocardial Fibrosis in Spontaneously Hypertensive Rats. Cardiovascular Research, 81, 601-609. https://doi.org/10.1093/cvr/cvn315

[12] Ezquerro, I.J., Lasarte, J.J., Dotor, J., Castilla-Cortazar, I., Bustos, M., Penuelas, I., Blanco, G., Rodriguez, C., Lechuga Mdel, C., Greenwel, P., Rojkind, M., Prieto, J. and Borras-Cuesta, F. (2003) A Synthetic Peptide from Transforming Growth Factor Beta Type III Receptor Inhibits Liver Fibrogenesis in Rats with Carbon Tetrachloride Liver Injury. Cytokine, 22, 12-20. https://doi.org/10.1016/S1043-4666(03)00101-7

[13] Santiago, B., Gutierrez-Canas, I., Dotor, J., Palao, G., Lasarte, J.J., Ruiz, J., Prieto, J., Borras-Cuesta, F. and Pablos, J.L. (2005) Topical Application of a Peptide Inhibitor of Transforming Growth Factor-Betal Ameliorates Bleomycin-Induced Skin Fibro- 
sis. Journal of Investigative Dermatology, 125, 450-455. https://doi.org/10.1111/j.0022-202X.2005.23859.x

[14] Ruiz-de-Erenchun, R., Dotor de las Herrerias, J. and Hontanilla, B. (2005) Use of the Transforming Growth Factor-Beta1 Inhibitor Peptide in Periprosthetic Capsular Fibrosis: Experimental Model with Tetraglycerol Dipalmitate. Plastic and Reconstructive Surgery, 116, 1370-1378.

https://doi.org/10.1097/01.prs.0000181694.07661.0d

[15] Howard, V.V. and Reed, M. (2004) Unbiased Stereology: Three-Dimensional Measurement in Microscopy. Garland Science, London.

https://doi.org/10.4324/9780203006399

[16] Mazaheri, M.K., Schultz, G.S., Blalock, T.D., Caffee, H.H. and Chin, G.A. (2003) Role of Connective Tissue Growth Factor in Breast Implant Elastomer Capsular Formation. Annals of Plastic Surgery, 50, 263-268.

https://doi.org/10.1097/01.SAP.0000046781.75625.69

[17] Kobayashi, J., Kikuchi, A., Aoyagi, T. and Okano, T. (2019) Cell Sheet Tissue Engineering: Cell Sheet Preparation, Harvesting/Manipulation, and Transplantation. Journal of Biomedical Materials Research Part A, 107, 955-967. https://doi.org/10.1002/jbm.a.36627

[18] Satish, L., Gallo, P.H., Baratz, M.E., Johnson, S. and Kathju, S. (2011) Reversal of TGF-Beta1 Stimulation of Alpha-Smooth Muscle Actin and Extracellular Matrix Components by Cyclic AMP in Dupuytren's-Derived Fibroblasts. BMC Musculoskeletal Disorders, 12, Article No. 113. https://doi.org/10.1186/1471-2474-12-113

[19] Lan, C.C., Fang, A.H., Wu, P.H. and Wu, C.S. (2013) Tacrolimus Abrogates TGFBetal-Induced Type I Col-lagen Production in Normal Human Fibroblasts through Suppressing p38MAPK Signalling Pathway: Implications on Treatment of Chronic Atopic Dermatitis Lesions. Journal of the European Academy of Dermatology and Venereology, 28, 204-215. https://doi.org/10.1111/jdv.12086

[20] Radovan, C. (1984) Tissue Expansion in Soft-Tissue Reconstruction. Plastic and Reconstructive Surgery, 74, 482-492. https://doi.org/10.1097/00006534-198410000-00005

[21] Stump, A., Holton 3rd., L.H., Connor, J., Harper, J.R., Slezak, S. and Silverman, R.P. (2009) The Use of Acellular Dermal Matrix to Prevent Capsule Formation around Implants in a Primate Model. Plastic and Reconstructive Surgery, 124, 82-91. https://doi.org/10.1097/PRS.0b013e3181ab112d

[22] Copcu, E., Sivrioglu, N., Sisman, N., Aktas, A. and Oztan, Y. (2003) Enhancement of Tissue Expansion by Calcium Channel Blocker: A Preliminary Study. World Journal of Surgical Oncology, 1, Article No. 19. https://doi.org/10.1186/1477-7819-1-19

[23] Laschke, M.W. and Menger, M.D. (2016) The Dorsal Skinfold Chamber: A Versatile Tool for Preclinical Research in Tissue Engineering and Regenerative Medicine. European Cells and Materials, 32, 202-215. https://doi.org/10.22203/eCM.v032a13 